\title{
Glucose Transporter Type 1 Deficiency Syndrome (Glut1) and Using Ketogenic Diet in Treatment of de Vivo Disease (A Case Reports)
}

\author{
Lukyanova ${ }^{1,2 *}$, Sushko IM ${ }^{1,2}$, Ayvazyan S0 ${ }^{1,2}$, Osipova $\mathrm{KV}^{1,2}$, Pyreva EA ${ }^{3}$ and Sorvacheva TN \\ ${ }^{1}$ Department of Health, St.Luka Scientific and Practical Center of Specialized Medical Care for Children, Russia \\ ${ }^{2}$ Medical Center Nevromed, Russia \\ ${ }^{3}$ Center for Nutrition and Biotechnology, Russia \\ ${ }^{4}$ Russian Medical Academy of Continuing Professional Education, Russia
}

Submission: July 21, 2017; Published: July 28, 2017

*Corresponding author: Luk'yanova, Department of Health, St.Luka Scientific and Practical Center of Specialized Medical Care for Children, Medical Center Nevromed, Moscow, Russia, Email: katerina17@gmail.com

\begin{abstract}
We present experience of ketogenic diet (KD) applying in the treatment of pharmacoresistant epilepsy in a patients with glucose transporter deficiency syndrome type I (GLUT1). We observed six children with refractory epilepsy due to GLUT1. The high effectiveness of KD in the treatment of GLUT1 was demonstrated. All patients were achieved complete absence of seizures and EEG abnormalities from the beginning of KD. We noticed positive shift in cognitive and speech development for all children. Antiepileptic drugs were stopped taking due to the stable remission. There was a further positive dynamics in intelligence, psycho-emotional sphere; the children began to go a nursery school and a special school. Thus, the ketogenic diet is high effectiveness and, perhaps, the only method for GLUT1 treatment.
\end{abstract}

Keywords: Ketogenic diet; Pharmacoresistant epilepsy; Intractable epilepsy; Glucose transporter deficiency syndrome type I (GLUT1)

\section{Introduction}

Glucose transporter type 1 deficiency syndrome (GLUT1) (synonyms: Glut1-DS, G1D, or De Vivo disease) is a rare genetic disorder mainly affecting the CNS. The disease was first described in 1991. About 500 patients have now been recorded around the world. The incidence ofGLUT1 is independent of gender, age, and nationality [1,2]

The disease is caused by a defect in the SLC2A1 gene, which encodes the glucose transporter responsible for transporting glucose from the blood to the brain across the blood-brain barrier - GLUT1 (type 1 glucose transporter). Mutations in the SLC2A1 gene can alter or completely block the function of GLUT1 protein, with the result that the brain lacks its main energy substrate, glucose, leading to progressive impairment to brain functions and the occurrence of the corresponding symptomatology.

The level of cerebral glucose metabolism is low during intrauterine development, increases linearly after birth, and reaches a peak at age three years, after which it remains high throughout the first decade of life, then gradually decreasing during the second decade of life. Thus, it can be suggested that the risk of clinical manifestations of GLUT1during intrauterine development is low, but then increases during infancy and early childhood.

The genetic aspects of GLUT1 include mutations in the SLC2A1 gene, generally spontaneous, though some families have been described as having autosomal dominant inheritance. GLUT1 is on rare occasions inherited as an autosomal recessive. The severity of the state is determined by the characteristics of the mutation. Prenatal diagnosis can be performed in high-risk pregnancies [3].

Children with GLUT1 have no phenotypic features at birth. The disease subsequently develops in two variants: the classical, or epileptic ( $90 \%$ of patients), and the non-epileptic (in $10 \%$ of patients). The classical variant typically manifests in the first months of life as polymorphous epileptic seizures: generalized tonic-clonic, myoclonic, atypical absence, atonic and myoclonic-atonic seizures. Seizures can occur with different frequencies - from monthly to daily, and are characterized by marked resistance to anticonvulsant therapy. Episodes of apnea, cyanosis, and paroxysmaleye movements can occur, and these 
can be preceded by convulsions. Motor impairments (ataxia, dystonia, spastic disorders) are then added in, and microcephaly forms.

The EEG often shows generalized or local epileptiform changes. An important pathognomonic feature of the disease is the regression of epileptic seizures and EEG anomalies after ingestion of food. The non-epileptic variant is dominated by motor disorders: paroxysmal dyskinesias (choreoathetosis/ dystonia), ataxia, and alternating hemiplegia of different grades of severity.

Patients frequently complain of headache. In some cases, hemolytic anemia forms part of the syndrome. Increases in clinical symptomatology during periods of hyperthermia and addition of inter current diseases are typical. All patients with GLUT1 experience progressive general developmental delay. The intellect is affected, as are verbal functions (dysarthria), increasing mental delay and changes in the motor domain.

The different variants of the disease and the severities of the various symptoms in each individual case cause significant difficulty in diagnosing GLUT1. Previously, the disease was diagnosed on the basis of the clinical picture and the results of laboratory studies, primarily - the assessment of glucose content in the cerebrospinal fluid (CSF).

With GLUT1, a decrease in glucose concentration is detected in CSF at normal or low lactate values against normoglycemia. The diagnostic criterion of the disease is a decrease in glucose content below $60 \mathrm{mg} / \mathrm{dl}(<40 \mathrm{mg} / \mathrm{dl}$ in $>90 \%$ of patients, 41 $52 \mathrm{mg} / \mathrm{dl}$ in $\sim 10 \%$ of patients). Currently, the final diagnosis is set after a genetic examination (DNA diagnostics).

Analysis of 3-0-methyl-D-glucose absorption in erythrocytes (35\%-74\% of the standard) is currently considered as the diagnostic gold standard for this disease [4]. SLC2A1 is the only gene where mutations are associated with the development of GLUT1 deficiency syndrome. SLC2A1 gene encoding GLUT1 protein, consists of 10 exons and 9 introns, is localized on the short arm of chromosome 1 (1p34.2) [5]. More than 150 mutations in SLC2A1 gene, which are the cause of GLUT1 deficiency syndrome, are described [6]. Pathogenic variants are represented by missense, nonsense mutations, which may include small intragenic deletions/insertions, as well as variants of splicing sites.

Proteins are carriers of glucose from GLUT protein group. These transport proteins facilitate passive diffusion of glucose through tissue seals by means of energy-independent mechanisms. The group includes 12 GLUT proteins. GLUT1 is expressed in endothelial cells of blood vessels that form part of the blood-brain barrier and is responsible for the penetration of glucose into the brain. GLUT2 is associated with the FanconiBickel syndrome, GLUT3 is responsible for the penetration of glucose through the neuronal plasma membrane, GLUT4 is an insulin-regulating glucose transporter of adipose tissue, cardiac muscle and skeletal muscles, and is responsible for insulin-mediated glucose transport, GLUT5 is expressed in the intestines, testicles and kidneys. The function of GLUT7 is currently unknown [7-9].

Currently the only effective approach to the treatment of GLUT1 consists of a ketogenic diet (KD). Consumption of a highfat, low-carbohydrate, ketogenic diet is accompanied by the formation of ketone bodies, which are able to cross the bloodbrain barrier using the MCT- 1 transporter, supporting alternative energy metabolism in the CNS [10-14].

The KD method was developed earlier for the treatment of drug-resistant epilepsy. In the Russian Federation, the only center that applies KD for the treatment of non-curable epilepsy is the State Budgetary Health Care Institution Scientific and Practical Center for Specialized Medical Care for Children n.a. V.F. Voyno-Yasenets Health Care Department of Moscow." In 2010, we have received a patent for invention No. 2404777 "A method for treating pharmaco-resistant epilepsy".

Published data and our own results [8-17] show that the use of a KD in epilepsy leads to improvements, with decreases in the frequency of seizures by $50-75 \%$ in more than half the patients and complete termination of seizures in $18 \%$. In practice, various modifications of the KD are used depending on the child's age and individual characteristics.

The KD is characterized by a high content of fat, which leads to metabolic acidosis, which can elicit side effects such as dyslipidemia, osteopenia, biliary dysfunction, gastroesophageal reflux, constipation, diarrhea, hyperuraturia, cardiopathy, etc. $[10,11,13,17]$. The phenomenon of aggravation of seizures has been described, along with changes in the emotional background (disinhibition, irritability) [12].

Patients on a KD therefore require careful observation for maintenance of the therapeutic level of ketosis and appropriate prophylaxis and correction of possible complications [15-18]. A KD was first used in GLUT1 in 1991. As evidenced by published data $[2,19]$, use of a KD in GLUT1 allows convulsive states to be eliminated and provides improvements in motor and cognitive functions and metabolic parameters, and, if prescribed early, improvements in the long-term neurological outcome [3].

According to the published data, 95\% of children with seizures with GLUT1 with KD showed a reduction in seizures by more than $50 \%$, and $80 \%$ - a reduction in seizures by more than $90 \%$ [20]. Many centers that treat GLUT1 give recommendations on the use of classical KD with a high ketogenic ratio of 4:1 and control the increase in ketones in blood serum or in urine, which is confirmed by our clinical data [20], but there are other data showing that there is no differences between patients using KD with a ratio of 4:1 (more strict) and lower ratios. 5 of 16 (31\%) patients adhering to a ketogenic ratio of $4: 1$ using KD were free of seizures compared with 21 of 38 (55\%) for lower ketogenic ratios [20]. 
Antiepileptic drugs (AED) are generally ineffective inGLUT1, or have only limited application, and some are contraindicated. This relates to barbiturates, which are often used in children in the first year of life, as well as valproates, acetazolamide, topiramate and zonisamide [21]. Treatment with methylxanthines should be avoided.

Alternative therapies are being developed recognizing that side effects occur in children with GLUT1 with prolonged use of KD. They include a modified Atkins diet (MDA) [22-25], ketoesters [26], triheptanone [27], alpha-lipoic acid [28] and acetazolamide [29].

In the southeast medical center of the University of Texas in Dallas, Dr. Juan M. Pascual conducts a number of new studies using triheptanon-C7 edible oil in respect of GLUT1. The ultimate goal of the study using the proposed $\mathrm{C} 7$ diet is to answer the question of whether C7 influences the effectiveness of neuropsychological activity (cognitive abilities) in patients with GLUT1 who observe and do not observe KD. There is a concern that C7 may have a negative effect on KD and, as a result, researchers intend to thoroughly study the potential compatibility/incompatibility.

Triheptanon (C7) is a food product considered as a possible therapeutic food. Perhaps, C7 will soon appear in the market as a therapeutic food along with other widely available food additives, such as vitamins (NANO VM) or MCT oil [30].

\section{Research Objective}

To increase the level of diagnostics of patients with glucose transporter type 1 deficiency syndrome (GLUT1) and to give recommendations on their treatment using KD.

\section{Subject of Research}

In the neuropsychiatric department of the State Budgetary Health Care Institution Scientific and Practical Center for Specialized Medical Care for Children n.a. V.F. Voyno-Yasenets Health Care Department of Moscow, patients with confirmed glucose transporter type 1 deficiency syndrome (De Vivo disease) associated with mutations in SLC2A1 gene have been observed for 6 years. The permission of the Ethical Committee of the Scientific and Practical Center for Specialized Medical Care for Children was obtained after the parents signed voluntary informed consent.

\section{Methods of Research}

Molecular-genetic research was conducted using modern diagnostic methods. The diagnosis of GLUT1 deficiency syndrome in the first examined patient was confirmed by method of targeted exome sequencing of the panel of 34 genes associated with early forms of epileptic encephalopathy, first developed in the genetic laboratory of the SPC of [31]. Isolation of genomic DNA from peripheral blood leukocytes and subsequent targeted exome sequencing was performed on MagNA Pure LC 2.0 and 454 Sequencing GS Junior (Roche) analyzers, respectively. Specialized
Internet resources were used to predict the conservatism and the degree of pathogenicity, clarifying the clinical significance of all identified variants in the genes: SIFT (Predict effects of nonsynonmous/missense variants), PolyPhen-2 (prediction of functional effects of human nsSNPs) и MutationTaster.

Samples of "1,000 Genomes", ESP6500, Exome Aggregation Consortium (ExAc) and Genome Aggregation Database (gnom $\mathrm{AD}$ ) were used to estimate the population frequencies of the identified variants. The OMIM database, specialized databases (GeneReviews (NCBI), HGMD (The Human Gene Mutation Database), LOVD (Leiden Open Variation Database), ClinVar (NCBI) and published data were used to assess the clinical relevance of the identified variants.

The detected mutation in SLC2A1 gene is represented by insertion of additional 6 nucleotides into the sequence-c.13051306insTGAAGA (p.V435VFI). The mutation is not registered in the control samples of "1000 genomes", ESP6500 and ExAC. Algorithms for predicting pathogenicity regard this substitution as pathogenic [32].

In 2 patients, mutations in SLC2A1 gene were determined by direct Sanger sequencing: c.115-2A $>$ G (IV S2-2A-G) andc.101A $>$ G (p.Asn34Ser). When performing the exome sequencing, mutation c.400G >A (p.Gly134Ser) was detected in 1 patient, which was not registered in the control samples of "1000 genomes", ESP6500 and ExAC. Algorithms for predicting pathogenicity regard this substitution as likely pathogenic.

The diagnosis of GLUT 1 deficiency syndrome in two patients was based on the clinical picture, data of biochemical analysis of the cerebrospinal fluid (a decrease in the level of glucose in CSF below the threshold level of $2.2-3.3 \mathrm{mmol} / \mathrm{l}$ ) and detection of pathogenic mutations in SLC2A1 gene. Two patients were diagnosed according to the clinical picture and biochemical analysis of CSF, since no informed consent was given to genetic testing.

Patients observed by us showed different types of mutations in SLC2A1 gene. Due to the small number of observations, it is not possible to carry out genotype-phenotypic correlations. All children were admitted with a diagnosis of cryptogenic epilepsy, a delay in psychomotor and speech development.

It is known from the anamnesis that all 6 patients from full-term normal pregnancies, independent births on time, had a good birth weight and a high APGAR scale score. The period of newborn childhood was uneventful. However, in the future, psycho-speech development slowed, ataxia and epileptic seizures appeared.

Part of the patients showed an increase in the frequency of seizures during "hunger", as well as lethargy and drowsiness. After eating, the children's condition improved, epileptic seizures disappeared. Further, all 6 children reported complaints of weakness in the legs that increased after physical exertion. EEG 
revealed epileptiform multiregional activity, periodically with secondary generalization. The effect of taking anticonvulsants was ambiguous.

Clinico-laboratory and instrumental studies showed a decrease in the concentration of glucose in CSF to $1.3-2.0 \mathrm{mmol} / \mathrm{l}$ (2.2-3.3mmol/l); the level of glycemia in blood was $4-5 \mathrm{mmol} / \mathrm{l}$ (standard 3.9-6mmol/l); the ratio of glucose in CSF to blood glucose was $0.3-0.45 \mathrm{mmol} / \mathrm{l}$ (standard $0.54-0.56 \mathrm{mmol} / \mathrm{l}$ ). The level of lactate in blood was increased (standard 0.5-2.2mmol/l)

EEG of some children before eating showed an irregular $\alpha$-rhythm, generalized discharges of epileptiform activity; after eating - a regular $\alpha$-rhythm, regress of epileptiform activity. Magnetic resonance imaging (MRI) of the brain showed no pathology in all patients. Based on the results of the studies, the following disease was diagnosed: Glucose transporter type 1 deficiency syndrome (GLUT1). Epilepsy.

A molecular genetic examination confirmed GLUT1 in 4 patients. These children were immediately taken to pass the KD course. The preliminary examination revealed no contraindications on the part of the somatic and neurological statuses for using this method of therapy. With the introduction of KD all children took AEDs in connection with epileptic attacks: myoclonic, myoclonic-atonic, complex absences and tonic-clonic. Often, myoclonias had a cascading behavior, intensified and becoming more frequent in a state of hunger. The neurological status showed motor disinhibition, expressive speech in the form of single words, poor vocabulary, dysarthria, diffuse muscle hypotension, motoric awkwardness, ataxia.

\section{Results}

A positive effect was observed after KD in the form of complete relief of epileptic seizures in all patients, absence of epileptiform activity according to video EEG monitoring data, improvement of EEG frequency characteristics, complete abolition of perinatal encephalopathy, however, the psycho-neurological deficiency in the form of hypotension, discoordination and dysarthria retained, but with expressed improvement.

Patients are being continuously monitored at home with regular monitoring of the children's condition, as provided for in the protocol. Symptomatic therapy was recommended to prevent and correct side effects: preparations of pancreatic enzymes, cholagogues, prokinetics and probiotics, as well as constant intake of multi-vitamin-mineral complexes.

Positive changes in cognitive and speech development have been achieved even after 3 months from the beginning of diet therapy: socialization of children has improved, interest in viewing television programs, surrounding subjects has increased, and phrase speech has appeared (separate phrases and sentences). At the same time, motoric disinhibition, restlessness, and periodical aggressiveness and irritancy retain in some children.
In our center, we use a metabolic drug - carnitine to improve metabolic processes, reduce manifestations of asthenic syndrome, MCT or coconut oil to increase the level of ketosis, gamma-aminobutyric acid and choline alphoscerate - to improve neurocognitive functions.

Later, in all patients on the background of KD administration and concomitant therapy, progress in cognitive and speech development grew, as well as interest in games, learning, expressive speech improved - simple sentences appeared, children started attending kindergartens and auxiliary schools. Quality of life of families and patients significantly improved.

Differential diagnostics of GLUT1 deficiency syndrome was performed with other pathological conditions causing neuroglycopenia (chronic or transient hypoglycemia in familial hyperinsulinism), convulsions in newborns and microcephaly, in particular, early manifestations of Rett syndrome, Angelmann syndrome, infantile forms of neuronal ceroid-lipofuscinosis; opsoclonus-myoclonus syndrome; cryptogenic epileptic encephalopathy with a delay in development; familial epilepsy with autosomal dominant type of inheritance; episodes of paroxysmal neurological dysfunction in response to carbohydrate intake, especially when combined with alternating hemiparesis, ataxia, cognitive impairment, or convulsions; motoric disorders, including dystonia [31].

\section{Discussion}

According to Columbia University (results obtained from many patients around the world and are similar to university results), patients with GLUT1 receiving KD can achieve a seizure reduction of more than $90 \%$ without using AEDs [20]. In our clinic, we managed to achieve $100 \%$ control of seizures, apparently due to a small number of patients.

According to global and our own published data, the overall results are better among those who started diet therapy at an earlier age. Patients diagnosed with GLUT1 in the earlier age were also prone to achieve better results than older patients. Screening of SLC2A1 gene will help speed up early diagnostics of GLUT1 and may lead to a faster KD appointment [20]. Alternative GLUT1treatments, such as the use of triheptanon, are the subject of clinical research; our foreign colleagues and we are convinced that the introduction of KD cannot be delayed.

The results of foreign and our studies contribute to approval of dietary therapy as the "gold standard" for GLUT1 treatment; it remains unclear what specific diet should be used. According to our colleagues, among children without seizures, the percentage of those observing KD and MCT (including triglycerides with an average chain length) diet was approximately equal to the percentage of those observing MDA and hypoglycemic diet, 74\% and $63 \%$, respectively [20].

Among the patients using classical KD, the ketogenic ratios vary considerably from 4:1 to 2:1, and also include the MCT diet. 
The results are almost identical among all diets and ratios [20]. We noticed a certain trend towards better signs of absence of seizures and improvement of cognitive functions among those with a 4:1 ratio, but nevertheless, this cannot reflect the modest size of our sampling. There is a dependence of control over seizures on the level of ketones in the serum (the higher the level). Monitoring of the comparison of ketone levels in blood and urine can be important, especially given that daily use of scarifiers in a sick child can be cumbersome and costly for the family in financial terms [20]. In our center, we determine the level of ketone bodies in both serum and urine. Two children (33\%) had a clear dependence of the absence of seizures on the level of ketone bodies. And finally, according to our data and the data of foreign authors, all patients with GLUT1 on the background of diet therapy should receive symptomatic therapy to improve tolerability of KD and reduce side effects from its application, as well as nutritional supplements and nootropic drugs to improve cognitive functions.

\section{Conclusion}

GLUT1 deficiency syndrome associated with impaired glucose transport to the brain, as a result of mutations in SLC2A1 gene, leads to neurological disorders with large phenotypic variety. Spinal puncture should be performed in each patient with suspected GLUT1 deficiency syndrome with glucose level measurement. Reduction in the glucose concentration in CSF of less than $2.2 \mathrm{mmol} / \mathrm{l}$ is an indication for the molecular genetics study of SLC2A1 gene and early KD administration.

Table 1

\begin{tabular}{|c|c|c|c|c|c|c|}
\hline \multirow[t]{2}{*}{ Symptom } & \multicolumn{6}{|c|}{ Symptoms in Patients } \\
\hline & Patient 1 & Patient 2 & Patient 3 & Patient 4 & Patient 5 & Patient 6 \\
\hline Sex & Female & Female & Male & Male & Male & Male \\
\hline Debut of seizures & 6 months & 6 weeks & 18 months & 14 months & 18 months & 11 months \\
\hline Type of seizures & $\begin{array}{c}\text { Dialectic with } \\
\text { atonic component } \\
(20 / \text { day }) \\
\text { Typical absences } \\
\text { with atonic } \\
\text { component } \\
\text { (multiple) }\end{array}$ & $\begin{array}{l}\text { Paroxysmal eye } \\
\text { movements } \\
\text { Myoclonic } \\
\text { seizures } \\
\text { (single) } \\
\text { Tonic-clonic } \\
\text { seizures up to } \\
5 \text { minutes } \\
\text { (every } 7-10 \\
\text { days) }\end{array}$ & $\begin{array}{l}\text { Myoclonic-astatic } \\
\text { (multiple) } \\
\text { Myoclonic } \\
\text { seizures, } \\
\text { sometimes } \\
\text { cascading } \\
\text { (multiple) }\end{array}$ & $\begin{array}{l}\text { Tonic-clonic } \\
\text { seizures up to } \\
5 \text { minutes } \\
\text { (6 total } \\
\text { seizures) }\end{array}$ & $\begin{array}{l}\text { Tonic } \\
\text { Right hemo } \\
\text { convulsions }\end{array}$ & $\begin{array}{c}\text { Myoclonia } \\
\text { (single) } \\
\text { Tonic-clonic } \\
\text { seizures up to } \\
\text { 5-7 minutes } \\
-2\end{array}$ \\
\hline Amount of PEPs before KD & 7 & 1 & 1 & 1 & & 1 \\
\hline Psycho-motoricdelay & + & + & + & + & + & + \\
\hline \multirow[t]{2}{*}{ Speech disorder } & - & + & + & + & + & + \\
\hline & $\begin{array}{c}\text { (no speech before } \\
\text { KD) }\end{array}$ & & & & & \\
\hline Microcephaly & - & + & - & + & - & + \\
\hline Ataxia & + & + & + & + & + & + \\
\hline Diffusemuscularhypotension & + & + & + & + & + & + \\
\hline Alternating hemiplegia & - & + & - & - & + & + \\
\hline Glucose level in CSF & $1.8 \mathrm{mmol} / \mathrm{l}$ & Not performed & $1.7 \mathrm{mmol} / \mathrm{l}$ & $2.0 \mathrm{mmol} / \mathrm{l}$ & $1.3 \mathrm{mmol} / \mathrm{l}$ & $1.7 \mathrm{mmol} / \mathrm{l}$ \\
\hline KD duration & 3 years & 1 year & 4 years & 5 months & 3 months & planned \\
\hline KD effectiveness & $100 \%$ & $100 \%$ & $100 \%$ & $100 \%$ & $100 \%$ & - \\
\hline PMD, EEG & $\begin{array}{l}\text { Improvement in } \\
\text { psychomotoric } \\
\text { development and } \\
\text { EEG normalization }\end{array}$ & & & & & \\
\hline Mutation in SLC2A1 gene & $\begin{array}{c}\text { c.1305- } \\
\text { 1306insTGAAGA } \\
\text { (p.V435VF1) }\end{array}$ & $\begin{array}{c}\text { c. } 115-2 A>G(I V \\
\text { S2-2A-G) }\end{array}$ & $\begin{array}{c}\text { c.101A>G } \\
\text { (p.Asn34Ser) }\end{array}$ & $\begin{array}{c}\text { c. } 400 \mathrm{G}>\mathrm{A} \\
\text { (p.Gly134Ser) }\end{array}$ & Recommended & Recommended \\
\hline
\end{tabular}


Satisfactory tolerability of KD at high efficiency (almost $100 \%$ ) in respect of epileptic seizures and significant improvement in motoric and cognitive functions is the grounds for its continued use in these patients, especially given the fact that diet therapy is currently the only effective GLUT1 treatment. Medico-genetic counseling of families where the child has a confirmed GLUT1 syndrome is important in planning the next pregnancy. The type of inheritance is autosomal-dominant, the risk of transmitting a pathogenic mutation from parents to the child is $50 \%$. When a mutation in SLC2A1 gene is detected in a proband, it is recommended to subject the parents to moleculargenetic testing, as parents may have a subclinical form of the disease [32]. The above medical cases show availability of KD in treatment of patients with such a rare and severe hereditary disease as glucose transporter type 1 deficiency syndrome (GLUT1) Table 1.

\section{References}

1. Leen WG, Wevers RA, Kamsteeg EJ, Scheffer H, Verbeek MM, et al. (2013) Cerebrospinal fluid analysis in the workup of GLUT-1 deficiency syndrome: a systematic review. JAMA Neurol 70(11): 1440-1444.

2. National Library of Medicine (2014) Genetics Home Reference your Guide to Understanding Genetic Conditions, GLUT1 deficiency syndrome. U.S. Department of Health \& Human Services, USA.

3. Luk'yanova EG, Aivazyan SO, Osipova KV, Pyr'eva EA, Sorvacheva TN (2016) Experience in the Use of a Ketogenic Diet in a Patient with Type I Glucose Transporter Defi ciency Syndrome (clinical observations) Neuroscience and Behavioral Physiology 46(9): 1090-1096.

4. Klepper J, Voit T (2002) Facilitated glucose transporter protein type 1 (GLUT1) deficiency syndrome impaired glucose transport into brain - a review. Eur J Pediatr 161(6): 295-304.

5. UCSC (2017) Human Genome Project. Univeristy of California, USA.

6. Leen WG, Klepper J, Verbeek MM, Leferink M, Hofste T, et al. (2010) Glucose transporter-1 deficiency syndrome: the expanding clinical and genetic spectrum of a treatable disorder. Brain 133(Pt 3): 655-670.

7. Joost HG, Bell GI, Best JD, Birnbaum MJ, Charron MJ, et al. (2002) Nomenclature of the GLUT/SLC2A family of sugar/polyol transport facilitators. Am J Physiol Endocrinol Metab 282(4): 974-976.

8. Mueckler M, Caruso C, Baldwin SA, Panico M, Blench I, et al. (1985) Sequence and structure of a human glucose transporter. Science 229(4717): 941-945.

9. Ho Y, Wang D, De Vivo D (2001) Glucose transporters. Wiley Encyclopedia of Molecular Medicine 50: 254-260.

10. Freeman J, Veggiotti P, Lanzi G, Tagliabue A, Perucca E (2006) The ketogenic diet: from molecular mechanisms to clinical effects. Epilepsy Research 68(2): 145-180.

11. Cheng CM, Hicks K, Wang J, Eagles DA, Bondy CA (2004) Caloric restriction augments brain glutamic acid decarboxylase-65 and -67 expression. Journal of Neuroscience Research 77: 270-276.

12. Yamada K, Ji JJ, Yuan H, Miki T, Sato S, et al. (2001) Brain amino acid metabolism and ketosis. J Neurosci Res 66(2): 272-281.

13. Morris AA (2005) Cerebral ketone body metabolism. J Inherit Metab Dis 28(2): 109-121.

14. Usacheva EL, Ayvazyan So, Sorvacheva TN, Pyr'eva EA, Shorina My (2004) The use of ketogenic diet in pharmacoresistant epilepsy treatment. Zh Nevrol Psikhiatr Im S S Korsakova 104(7): 29-34.
15. Coppola G, Veggiotti P, Cusmai R, Bertoli S, Cardinali S, et al. (2002) The ketogenic diet in children, adolescents and young adults with refractory epilepsy: an italianmulticentric experience. Epilepsy Res 48(3): 221-227.

16. Kossoff EH, McGrogan JR (2005) Worldwide use of the ketogenic diet. Epilepsia 46(2): 280-289.

17. Sorvacheva TN, Pyr'va EA, Kon' IYa, Usacheva EL, Ayvazyan SO, et al. (2004) Ketogenic diet in the complex treatment of pharmacoresistant forms of epilepsy in children: clinical evaluation of efficiency. Pediatry $2: 41-45$.

18. Stafstrom CE (2004) Dietary approaches to epilepsy treatment: old and new options on the menu. Epilepsy Currents. 4(6): 215-222.

19. Klepper J, Fischbarg J, Vera JC, Wang D, De Vivo DC (1999) GLUT1 deficiency: barbiturates potentiate haploinsufficiency in-vitro. Pediatr Res 46(6): 677-683.

20. Kass HR, Winesett SP, Bessone SK, Turner Z, Kossof EH (2016) Use of dietary therapies amongst patients with GLUT1 deficiency syndrome. Seizure 35: 83-87.

21. Wang D, Pascual JM, De Vivo D (2012) Glucose Transporter Type 1 Deficiency Syndrom. Gene Reviews.

22. Klepper J, Leiendecker B (2013) Glut1 deficiency syndrome and novel ketogenic diets. J Child Neurol 28(8): 1045-1048.

23. Ito Y, Oguni H, Ito S, Oguni M, Osawa M (2011) A modified Atkins diet is promising as a treatment for glucose transporter type 1 deficiency syndrome. Dev Med Child Neurol 53(7): 658-663.

24. Haberlandt E, Karall D, Jud V, Baumgartner SS, Zotter S, et al. (2014) Glucose transporter type 1 deficiency syndrome effectively treated with modified Atkins diet. Neuropediatrics 45(2): 117-119.

25. Ramm-Pettersen A, Nakken KO, Skogseid IM, Randby H, Skei HEB, et al. (2013) Good outcome in patients with early dietary treatment of GLUT1 deficiency syndrome: results from a retrospective Norwegian study. Dev Med Child Neurol 55(5): 440-447.

26. Viggiano A, Pilla R, Arnold P, Monda M, D'Agostino D, et al. (2015) Anticonvulsant properties of an oral ketone ester in a pentylenetetrazole-model of seizure. Brain Res 1618: 50-54.

27. Pascual JM, Liu P, Mao D, Kelly DI, Hernandez A, etal. (2014) Triheptanoin for glucose transporter type 1 deficiency (G1D): modulation of human ictogenesis, cerebral metabolic rate, and cognitive indices by a food supplement. JAMA Neurol 71(10): 1255-1265.

28. Shay KP, Moreau RF, Smith EJ, Smith AR, Hagen TM (2009) Alpha-lipoic acid as a dietary supplement: molecular mechanisms and therapeutic potential. BiochimBiophysActa 1790(10): 1149-1160.

29. Anheim M, Maillart E, Vuillaumier-Barrot S, Flamand-Rouviere C, Pineau F, et al. (2011) Excellent response to acetazolamide in a case of paroxysmal dyskinesias due to GLUT1-deficiency. J Neurol 258(2): 316-317.

30. Pascual JM, Liu P, Mao D, Kelly DI, HernandezA, etal. (2014) Triheptanoin for glucose transporter type I deficiency (G1D): modulation of human ictogenesis, cerebral metabolic rate, and cognitive indices by a food supplement. JAMA Neurol 71(10): 1255-65.

31. Brukhanova NO, Zhilina SS, Belenikin MS, Mutovin GR, Ayvazyan SO, et al. (2015) Capabilities of genetic testing in resistant forms of epilepsy. Journal of Pediatryna G N Speransky 94(5): 77-80.

32. Kozhanova TV, Zhilina SS, Meshcheryakova TI, Aivazyan SO, Osipova $\mathrm{KV}$, et al. (2017) Clinical and molecular-genetic diagnostics of glucose transporter type 1 deficiency syndromein patients of the psychoneurological department. Journal of Pediatryna GN Speransky No. 1, 2017, pp.156-164. 
Your next submission with Juniper Publishers will reach you the below assets

- Quality Editorial service

- Swift Peer Review

- Reprints availability

- E-prints Service

- Manuscript Podcast for convenient understanding

- Global attainment for your research

- Manuscript accessibility in different formats ( Pdf, E-pub, Full Text, Audio)

- Unceasing customer service

Track the below URL for one-step submission https://juniperpublishers.com/online-submission.php 